\title{
POLÍTICAS DE OBTENÇÃO DOS TERRITÓRIOS DOS ASSENTAMENTOS RURAIS EM MINAS GERAIS
}

\section{TERRITORY ACQUISITION POLICIES OF AGRARIAN REFORM SETTLEMENTS IN MINAS GERAIS}

\author{
Estevan Leopoldo de Freitas Coca \\ Universidade Federal de Alfenas, Instituto de Ciências da Natureza, Alfenas, MG, Brasil \\ estevan.coca@unifal-mg.edu.br
}

\section{Resumo}

A experiência de reforma agrária brasileira é uma das mais complexas do mundo. Ela combina políticas de obtenção de terras com potencial de desconcentração da estrutura fundiária, a exemplo das desapropriações, com outras que, apesar de importantes, não geram a desterritorialização do agronegócio, como é o caso da compra. Diversos trabalhos têm abordado essa realidade, porém, nenhum trata especificamente do estado de Minas Gerais, o qual dentre as unidades federativas brasileiras se destaca por concentrar uma das mais acentuadas conflitualidades no campo. Por isso, neste trabalho tomo como recorte o estado de Minas Gerais para discutir a diversidade de políticas de obtenção de terras na reforma agrária brasileira. Como procedimentos metodológicos realizei levantamentos bibliográficos e documentais, além de ter sistematizado dados sobre assentamentos rurais disponibilizados pelo Banco de Dados da Luta pela Terra (DATALUTA). Dentre os principais resultados, demonstro que a desapropriação é a política de obtenção mais utilizada em Minas Gerais, porém, ela coexiste com outras como o reconhecimento e a compra/doação.

Palavras-chave: Reforma agrária. Assentamentos rurais. Políticas de obtenção. Conflitualidade. Minas Gerais.

\begin{abstract}
Brazilian agricultural reform represents one of the most complex experiences in the world. It combines land acquisition policies with the potential to deconcentrate land structure, expropriation is an example, with others that, although important, do not generate the deterritorialization of agribusiness, as is the case with purchase. Various studies have investigated this reality, however, none of them considered the state of Minas Gerais, which is shown to concentrate one of the most important areas of conflict in the countryside among the Brazilian federative units. Therefore, in this work, I focus on the state of Minas Gerais to discuss the diversity of land use policies in Brazilian agricultural reform. As a methodological procedure, I carried out bibliographic and document review, in addition to systematizing data on rural settlements provided by the Luta pela Terra Database (DATALUTA). Among the main findings, I demonstrate that expropriation is the most used policy in Minas Gerais, however, it coexists with others such as recognition and purchase/donation.
\end{abstract}


Keywords: Land reform. Agrarian reform settlements. Acquisition policies. Conflictuality. Minas Gerais.

\section{Introdução}

No Brasil, com o golpe jurídico-parlamentar-midiático de 2016, houve uma considerável diminuição nos dados de assentamentos rurais criados ou incorporados pelo Governo Federal. Como resultado disso, em 2017, foram assentadas apenas 1.900 famílias, caracterizando o terceiro pior desempenho anual desde a redemocratização, em 1985 (somente em 1985 e 2016 foram assentadas menos famílias do que em 2017) (REDE DATALUTA, 2018). Ao mesmo tempo, por mais que menor do que em outros contextos, a demanda por reforma agrária apresentada por meio das ocupações de terras continua significativa, de modo que em 2017, 20.596 famílias participaram dessas ações, além de outras 396.691 que estiveram em manifestações (concentração em espaços públicos, ocupações de prédios públicos, marchas, caminhadas, acampamentos, romarias, bloqueios e outros) (REDE DATALUTA, 2018). Assim, constata-se que a Questão Agrária brasileira ainda não foi resolvida e que por isso, a reforma agrária, enquanto política mitigadora dos seus efeitos negativos, se mantém como um tema de fundamental importância para a discussão sobre o modelo de desenvolvimento para o campo e as cidades no país (FERNANDES, 2018).

Reconhecendo esse fato e tendo como referência o estado de Minas Gerais, no presente artigo visa-se discutir as políticas de obtenção dos territórios dos assentamentos rurais como um dos elementos que caracterizam a reforma agrária brasileira no presente. A importância dessa discussão reside no fato de que no Brasil, a reforma agrária tem sido implementada tanto por políticas que possuem potencial de reformular a estrutura fundiária, a exemplo das desapropriações, como também por outras que, apesar de contribuírem para que os camponeses tenham o título de propriedade da terra ou o direito de concessão de uso, não desterritorializam o agronegócio, como ocorre no caso das regularizações e dos reconhecimentos (OLIVEIRA, 2007). Minas Gerais foi escolhida como recorte para esse trabalho por concentrar algumas das principais políticas de obtenção de terras que têm sido utilizadas na efetivação da reforma agrária brasileira. 
$\mathrm{Na}$ primeira parte do trabalho consta o referencial teórico, onde a reforma agrária é abordada com base na conflitualidade entre os modelos de desenvolvimento do agronegócio e do campesinato. Na segunda parte, é apresentada a metodologia que foi adotada para a confecção desse texto. Por fim, na terceira parte, constam os resultados, de modo que são evidenciados os dados sobre as políticas de obtenção de terras que deram origem aos assentamentos rurais no estado de Minas Gerais. O principal resultado indica que, além da desapropriação, em Minas Gerais a reforma agrária avança por meio de políticas que não possuem o mesmo potencial de reformulação da estrutura fundiária, o que emerge como resultado da complexidade da Questão Agrária nessa unidade federativa.

Destaca-se ainda que, o presente trabalho traz resultados do projeto de pesquisa e extensão "Banco de Dados da Luta pela Terra (DATALUTA) - Sul de Minas Gerais", que tem sido desenvolvido pelo Grupo de Estudos Regionais e Socioespaciais (GERES), da Universidade Federal de Alfenas (UNIFAL-MG). Ao lado de outros 14 grupos de pesquisa de diversas instituições brasileiras, o GERES compõe o coletivo do pensamento Rede DATALUTA que tem como parte de sua finalidade a produção de dados e informações sobre a Questão Agrária brasileira, a exemplo de movimentos socioterritoriais, ocupações de terras, manifestações, assentamentos rurais, estrutura fundiária e estrangeirização de terras. Por meio da participação nesse coletivo do pensamento, o GERES tem contribuído para o conhecimento e interpretação da Questão Agrária em Minas Gerais.

\section{Referencial teórico}

Nesse artigo, os assentamentos rurais são lidos por meio da abordagem geográfica como territórios do campesinato que se qualificam como triunfos e trunfos da luta pela terra, (FERNANDES, 2000; RAFFESTIN, 1993). Ao mesmo tempo em que significam a conquista de um espaço de vida e produção para os camponeses e camponesas, eles também servem como referência para outras lutas, haja vista que não encerram a Questão Agrária. Percebe-se isso pelo fato que, historicamente, mesmo nos períodos com maior incidência de assentamentos rurais criados, as ocupações de terras não cessaram (REDE DATALUTA, 2018). 
Ao serem criados, os assentamentos rurais ferem a hegemonia do agronegócio, porém, a conflitualidade entre os modelos de desenvolvimento para o campo permanece. Eles são conquistados pelos movimentos socioterritoriais por meio da pressão realizada com as ocupações de terras e também da reivindicação de áreas já ocupadas, porém, ainda não transferidas legalmente (título de propriedade ou concessão de uso) ao campesinato. Levar esses casos em consideração é importante para efeito da justiça social, na medida em que, especialmente em meados do século XX, grande contingente de brasileiros migrou sem o título da terra para áreas de expansão da fronteira agrícola, efetivando uma reforma agrária espontânea (IANNI, 1979). Essa diversidade de processos que geram os territórios dos assentamentos rurais no Brasil é consequência da grande extensão territorial do país, dos avanços e contrastes da fronteira agropecuária e da histórica situação de subalternidade a que têm sido submetidos camponeses e indígenas na orientação do modelo de desenvolvimento agrícola ou agrário.

$\mathrm{Na}$ atualidade, o campo e a floresta brasileiros caracterizam-se por uma intensa conflitualidade entre os modelos de desenvolvimento do agronegócio, de um lado e do campesinato e indígenas, de outro. Enquanto para o agronegócio a terra representa uma mercadoria, para camponeses e indígenas ela possui valor de uso. Contando com grande parte do financiamento público destinado ao campo e de grande aceitação por parte da mídia e dos poderes Executivo, Legislativo e Judiciário, o agronegócio avança de modo rápido, intenso e predatório sobre o os territórios camponeses e indígenas (ALMEIDA, 2010), remetendo ao que Harvey (2005) tem denominado "acumulação por espoliação". Nesse sentido, estamos diante de uma nova etapa do violento processo de acumulação capitalista, o qual, por ser constante, exige a inserção de novos territórios e sujeitos na sua dinâmica reprodutiva. Como resultado disso, no Brasil, especialmente por meio da produção de grãos e da criação de gado, o agronegócio tem sido o responsável pelo aumento do consumo de agrotóxicos, a contaminação e assoreamento de corpos d'água, o desmatamento e outros. Ao mesmo tempo em que ele se apresenta como uma expressão da modernidade, em razão da otimização das práticas produtivas via uso de maquinários e insumos químicos, ele também acentua a desintegração socioeconômica de comunidades do campo e da floresta, além de dilapidar o meio ambiente. 
Contudo, esse processo não é uniforme e eivado de contradições. Como prova disso, por meio da reforma agrária, especialmente desde a redemocratização, em 1985, o campesinato tem conquistado novos territórios por meio da implantação dos assentamentos rurais (COCA, 2013; FERNANDES, 2000). Eles não são consequência de uma ação deliberada do Estado, mas da pressão realizada pelos movimentos socioterritoriais que denunciam a desigual distribuição fundiária brasileira e a não observância da função social da terra, assim como os efeitos perversos que esses problemas geram direta ou indiretamente, dentre os quais, a miséria no campo e nas cidades. Nesse sentido, a reforma agrária brasileira é um exemplo de que, apesar de responder com maior intensidade aos interesses das classes hegemônicas, por meio das lutas sociais, ele também traz algumas aberturas que permitem a reprodução das classes subalternas. Isso se dá devido ao fato de que o capitalismo e o modelo democrático são contraditórios e incompletos.

Remetendo à abordagem geográfica, considera-se que os territórios são formados pela diversidade das relações de poder, de modo que os assentamentos rurais são lidos aqui como territórios que estão atrelados à propriedade da terra, estando assim, dentro do território do Estado-Nação (espaço de governança), influenciando-o e sendo influenciados por ele. Assim, para entende-los é necessário considerar aspectos como as intencionalidades e articulações escalares das políticas públicas, a relação com os mercados consumidores, as perspectivas dos camponeses e camponesas assentados em relação ao seu modo de viver e trabalhar e outros.

No caso de um país com grande diversidade social, cultural e ambiental como o Brasil, o entendimento sobre a produção dos territórios dos assentamentos rurais também exige que se considere a pluralidade de sujeitos e identidades dos beneficiários da reforma agrária assim como os espaços nos quais se reproduzem (por exemplo: campo, florestas, áreas comunais ou até mesmo a reterritorialização em razão da construção de obras de infraestrutura) (COCA, 2015). São beneficiários da reforma agrária brasileira povos e comunidades como sem-terra, atingidos por barragens, quilombolas, fundos de pasto, faxinais, geraizeiros e outros. Enquanto alguns desses têm por objetivo entrar na terra, outros já estão nela, porém, ainda não possuem o título de propriedade. Esse é o motivo para que, além da desapropriação de terras, a reforma agrária brasileira também avance por meio de políticas como a compra, a doação, o 
reconhecimento, a transferência e principalmente, a regularização fundiária. Sua interpretação exige que se considere processos mais amplos, especialmente a própria formação econômica e territorial do Brasil com todas as suas contradições.

Ainda, vale lembrar que as reformas agrárias do século XXI devem ser lidas dentro de um amplo escopo que envolve a multidimensionalidade do desenvolvimento, indo além das perspectivas de caráter essencialmente econômico (WHITE; BORRAS JR.; HALL, 2014). Assim, apesar de concordar com a leitura de Griffin, Khan e Ickowitz(2002) de que um genuíno processo de reforma agrária deve se dar de modo redistributivo, rompendo com a hegemonia dos grandes proprietários e também da cidade em relação ao campo, aqui é pontuado que no caso brasileiro, além das desapropriações, a territorialização do campesinato via reforma agrária também se dá através de políticas que lhes garante a concessão de uso ou o título de propriedade de áreas já ocupadas. Por mais que tais ações não modifiquem a estrutura fundiária objetivo mais importante da reforma agrária - ao menos elas contribuem para que os camponeses e camponesas beneficiários reproduzam seu modo de vida e trabalho por meio do acesso e/ou permanência legal à terra.

Com isso, propõe-se discutir a reforma agrária como um processo de desenvolvimento territorial que visa romper com a ótica meramente economicista que é frequentemente direcionada ao campo pelo Estado (FERNANDES, 2008). Ela não é apenas uma medida de caráter compensatório com frágil potencial de alteração do status quo. Além de contribuir para a superação da exclusão a que são submetidos milhões de trabalhadores em razão do êxodo rural e do crescimento desgovernado das cidades, ela também fomenta a agricultura camponesa que possui grande potencial de contribuir com a superação de problemas como o aquecimento global e o abastecimento alimentar (Van der PLOEG, 2016).

\section{Metodologia}

Os procedimentos metodológicos adotados para a produção desse trabalho se dividem em três eixos:

i) primeiro foi feito um levantamento teórico e conceitual sobre a abordagem geográfica dos territórios e as políticas de reforma agrária. Foram consultados materiais impressos 
e digitais, os quais posteriormente foram fichados com base nos conceitos-chave que orientam o presente artigo;

ii) num segundo momento foram definidas a área de estudo e a escala temporal. Desse modo, Minas Gerais foi eleita por concentrar uma diversidade de exemplos de disputas territoriais entre o campesinato e o agronegócio (CLEPS JÚNIOR et al., 2018). Como o primeiro assentamento de Minas Gerais data de 1986 (Projeto de Assentamento Federal Vereda Grande, em Urucaia) (FERNANDES, 2000), decidiu-se partir dessa data até o ano de 2017. Esse limite foi estabelecido pelo fato de ainda não termos os dados de 2018 e 2019 e;

iii) consulta e sistematização de dados e informações sobre assentamentos rurais obtidos por meio do Banco de Dados da Luta pela Terra (DATALUTA), que é produzido pela Rede DATALUTA. Ressalta-se que no DATALUTA os dados e informações sobre assentamentos rurais são organizados com base nos relatórios anuais do Instituto Nacional de Colonização e Reforma Agrária (INCRA) e trazem informações como: localização, capacidade de famílias, número de famílias assentadas, área, tipo, processo legal (portarias, decretos etc.), data da obtenção da terra, data de criação e o que é mais importante para a discussão aqui realizada, a política de obtenção utilizada. Esses dados foram organizados num cartograma (Figura 01), elaborado por meio do software Philcarto e da Tabela 01, elaborada no software Microsoft Excel.

\section{Resultados}

Entre 1986 e 2017 foram implantados 415 assentamentos rurais no estado de Minas Gerais, com 25.090 famílias e 1.054.914 ha. (Tabela 01). Isso faz com que em escala nacional, Minas Gerais ocupe a $8^{\text {a }}$ posição no número de assentamentos criados, a $14^{\mathrm{a}}$ no número de famílias assentadas e a $12^{\mathrm{a}}$, ao lado de Goiás, na área ocupada (REDE DATALUTA, 2018). Essa discrepância entre a posição ocupada por essa unidade federativa no número de assentamentos em comparação com a área e a família se explica pelo fato de que os projetos criados no Norte do país possuem maiores módulos rurais, pois muitos deles são gerados por territorialidades agroextrativistas. 
Tabela 01: Minas Gerais - Políticas de obtenção dos assentamentos rurais - 1986-2017

\begin{tabular}{c|c|c|c|c|c|c}
\hline $\begin{array}{c}\text { Política de } \\
\text { obtenção }\end{array}$ & $\begin{array}{c}\mathbf{N}^{\mathbf{0}} \text { de } \\
\text { assentamentos }\end{array}$ & $\mathbf{\%}$ & $\begin{array}{c}\mathbf{N}^{\mathbf{0}} \text { de } \\
\text { famílias }\end{array}$ & $\begin{array}{c}\text { Áreaem } \\
\text { ha }\end{array}$ & $\mathbf{\%}$ \\
\hline Adjudicação & 1 & 0,24 & 13 & 0,05 & 300 & 0,03 \\
\hline Compra e venda & 22 & 5,30 & 1.050 & 4,18 & 32.969 & 3,13 \\
\hline Desapropriação & 324 & 78,07 & 18.230 & 72,66 & 838.112 & 79,45 \\
\hline Doação & 7 & 1,69 & 975 & 3,89 & 32.117 & 3,04 \\
\hline Reconhecimento & 54 & 13,01 & 4.659 & 18,57 & 147.221 & 13,96 \\
\hline Transferência & 3 & 0,72 & 43 & 0,17 & 639 & 0,06 \\
\hline NãoInformado & 4 & 0,96 & 120 & 0,48 & 3.556 & 0,34 \\
\hline Total & $\mathbf{4 1 5}$ & $\mathbf{1 0 0}$ & $\mathbf{2 5 . 0 9 0}$ & $\mathbf{1 0 0}$ & $\mathbf{1 . 0 5 4 . 9 1 4}$ & $\mathbf{1 0 0}$ \\
\hline
\end{tabular}

Fonte: DATALUTA, 2019. Org. Estevan Coca.

Em Minas Gerais, a desapropriação foi a política mais utilizada, com maior número de famílias e da área. Dentre as políticas de obtenção de terras que têm sido utilizadas para a criação de assentamentos rurais no Brasil, ela é a que possui o maior potencial de desconcentração da estrutura fundiária e consequentemente, de alteração da correlação de forças no campo (GIRARDI, 2008; OLIVEIRA, 2007). Elas se enquadram no que Griffin, Khan e Ickowitz(2002) chamam de processo de "reforma agrária redistributiva" ou que Gárcia-Nossa (1973) denominou como "reforma agrária radical".

Em parte, a predominância das desapropriações em Minas Gerais se explica pelo fato de que as mesorregiões Norte de Minas Gerais e Triângulo Mineiro/Alto do Parnaíba - onde está a maior parte dos assentamentos originados pela desapropriação nessa unidade federativa (Figura 01) - se caracterizam por intensa conflitualidade manifestada por meio das ocupações de terras (CLEPS JÚNIOR et al., 2018; REDE DATALUTA, 2018). Como destacado em Fernandes (2000), os dados sobre a Questão Agrária brasileira denotam que existe uma relação entre áreas ocupadas por movimentos socioterritoriais e desapropriações para implementação de assentamentos rurais. Isso porque, as ocupações dão publicidade ao não cumprimento da função social da terra prevista pela Constituição Federal brasileira de 1988, forçando o Estado a desterritorializar grandes proprietários por meio de políticas de reforma agrária. 
Essa correlação entre a ocupação de terras e a criação de assentamentos rurais também pode ser percebida por meio da compra e venda, porém, com diferentes impactos na estrutura fundiária e no processo de reprodução do capital. Na Figura 01 percebe-se que a maior parte dos assentamentos rurais oriundos de tal processo está nas áreas com grande concentração de desapropriações de terras, que como dito, são expressão da intensa conflitualidade entre o campesinato e o agronegócio. A compra e venda ocorre quando o Estado não pode desapropriar a área que motiva o conflito entre o campesinato e o capital. Nesse caso, ao invés de serem pagos com Títulos da Dívida Agrária (TDA's), como ocorre nas desapropriações, os proprietários recebem em dinheiro. Assim, apesar de permitirem ao campesinato o acesso à terra, tais ações também possibilitam a reprodução do capital em outros territórios ou em outras atividades produtivas, ou seja, não existe uma profunda alteração da estrutura fundiária e/ou das relações de poder via desterritorialização agronegócio.

Seguindo a desapropriação, a maior representatividade numérica é do reconhecimento de terras, que ocupa a segunda posição no número de assentamentos, de famílias e da área $(13,01 \%, 18,57 \%$ e $13,9 \%$ do total estadual, respectivamente). Esse tipo de política de obtenção ocorre quando o assentamento rural é criado por estados ou municípios e depois, incorporado aos dados do Governo Federal para que as famílias beneficiárias passem a ter acesso a créditos de instalação e outras políticas de fomento, a exemplo de modalidades específicas do Programa Nacional de Fortalecimento da Agricultura Familiar (PRONAF) e do Programa de Aquisição de Alimentos (PAA). No caso de Minas Gerais, dos 54 assentamentos reconhecidos pelo INCRA, 37 estão relacionados à construção de barragens. Ou seja, são formas de compensação às famílias atingidas pelos processos de alagamento ocasionados por essas grandes obras de infraestrutura, especialmente os ribeirinhos. Não à toa, pela Figura 01 é possível constatar que a maior parte dos assentamentos que foram reconhecidos pelo Governo Federal estão localizados em municípios que possuem rios e comunidades impactados por grandes obras de infraestrutura, especialmente nas mesorregiões Norte de Minas e Jequitinhonha. São exemplos os municípios Botumirim e Jaíba. O primeiro está na área atingida pela Usina Hidrelétrica de Irapé, criada em 2002, e possui 5 assentamentos rurais reconhecidos pelo Governo Federal. O segundo sofreu consideráveis impactos com a construção da Usina Hidrelétrica de Três Marias, inaugurada em 1962, e possui 6 
assentamentos rurais reconhecidos pelo Governo Federal. Como demonstrado em Coca (2011), no caso das políticas de reforma agrária, faz-se mister considerar que os atingidos por barragem são camponeses com identidade diferente dos sem-terra, haja vista que enquanto nos segundos a territorialidade agropecuária é que a mais se destaca, nos primeiros, também deve-se considerar o vínculo com a água.

Os 7 assentamentos obtidos por meio da doação de terras estão localizados em quatro mesorregiões: Metropolitana de Belo Horizonte, Vale do Rio Doce e Norte de Minas. A doação ocorre em casos em que instituições ou particulares, sem o uso de obrigatoriedade ou coação, destinam terras sob sua responsabilidade para a criação dos assentamentos rurais. Como exemplo tem-se o Projeto de Assentamento Federal Herbert de Souza (Betinho), na mesorregião Norte de Minas. Ele foi criado na segunda metade da década de 1990 nas terras da usina Malvina S/A, que estava em processo de falência, possuindo diversos processos na Justiça, especialmente de dívidas trabalhistas. Após o assentamento ter sido efetivado pelo Governo Estadual, no ano de 1998 houve uma grande pressão por parte do antigo arrendatário junto ao INCRA pela reversão do processo. Todavia, em janeiro de 1999, o então governador Itamar Franco, do Partido da Mobilização Democrática Brasileira (PMDB), adjudicou junto à União as terras do assentamento, possibilitando que elas fossem consideradas de interesse social e assim, destinadas ao quadro da reforma agrária em âmbito nacional (LADEIA, 2003).

Por fim, a transferência e a adjudicação são as políticas de obtenção de terras com menor expressividade em Minas Gerais. A transferência é uma medida administrativa que se dá por exigência do Estado como forma de repassar a responsabilidade por um imóvel para fins de reforma agrária, quase sempre em áreas onde existem conflitos entre os camponeses e os proprietários. Como exemplo tem-se o Projeto de Assentamento Resistência, localizado em Funilândia, na mesorregião Metropolitana de Belo Horizonte, o qual foi criado em terras pertencentes à Santa Casa de Belo Horizonte e que não estavam sendo aproveitadas para fins produtivos, justificando sua destinação para a reforma agrária (MST, 2018). Por sua vez, a adjudicação foi utilizada apenas no Projeto de Assentamento Federal Nova Conquista II, em Campo do Meio, na mesorregião Sul e Sudoeste de Minas Gerais. Nesse caso, o Governo Estadual destinou à União parte das terras da falida usina Ariadnópolis para fins de reforma agrária como forma de atender à reivindicação de camponeses e 
camponesas articulados pelo Movimento dos Trabalhadores Rurais Sem-Terra (MST), muitos dos quais antigos trabalhadores dessa empresa (COCA, et al., 2018).

Assim, constata-se que além da desapropriação, que possui desempenho majoritário em Minas Gerais, outras políticas de obtenção de terras compõem a atualidade da reforma agrária nessa unidade federativa. $\mathrm{O}$ reconhecimento desse processo contribui para a leitura sobre a diversidade das disputas territoriais entre o campesinato e o agronegócio como parte da Questão Agrária contemporânea.

Figura 01: Minas Gerais - Número de assentamentos conforme as políticas de obtenção de terras - 1986-2017

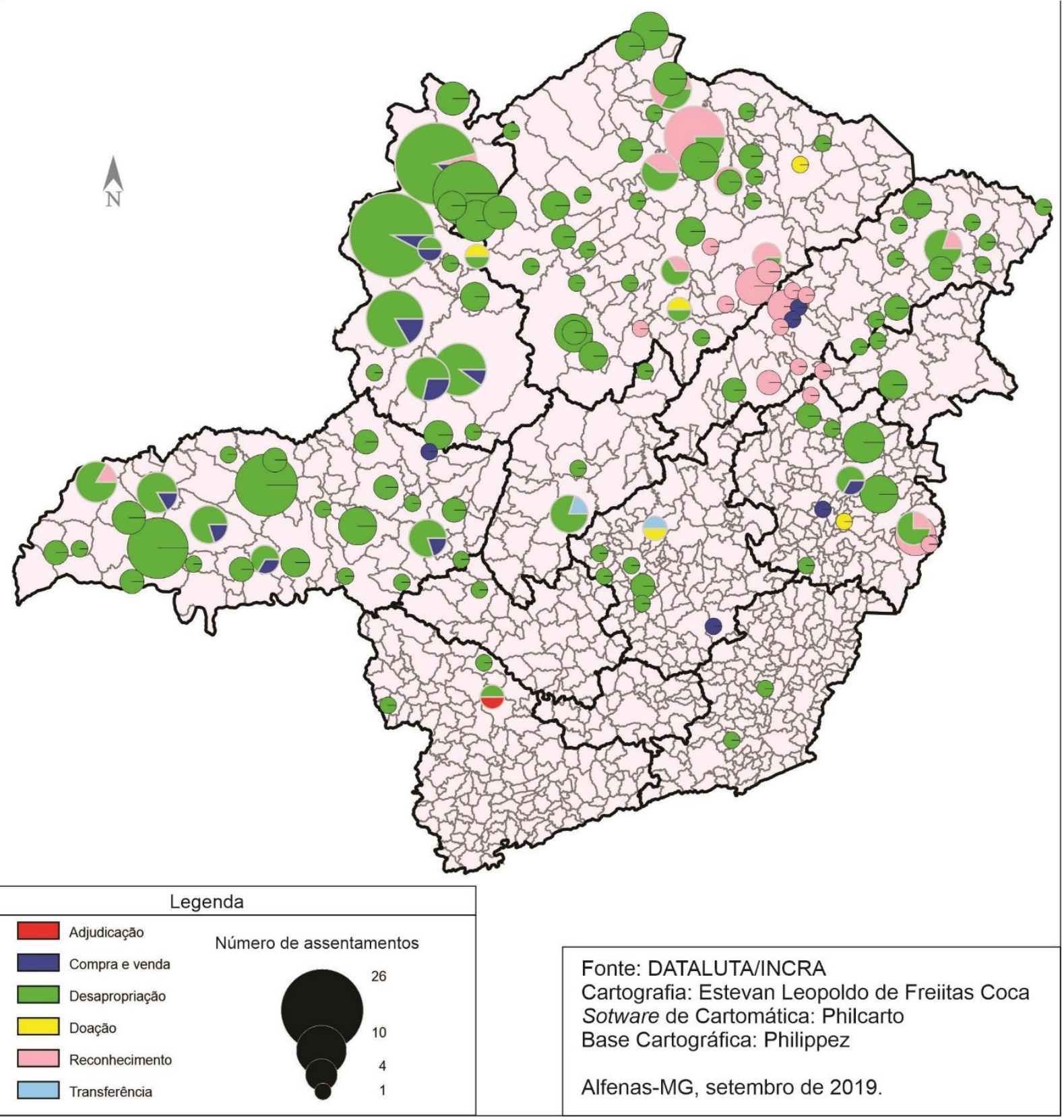




\section{Considerações finais}

A reforma agrária é uma das expressões da constante disputa territorial entre o campesinato e o agronegócio pela orientação do modelo de desenvolvimento para o campo no Brasil. Por mais que ela não represente a resolução da Questão Agrária, ao menos cria condições para a reprodução do modo de vida e trabalho do campesinato. Além disso, ela também contribui direta ou indiretamente para a mitigação de problemas do campo e da cidade como o aquecimento global, o abastecimento alimentar, a reprodução da pobreza e da miséria etc. Dada a grande diversidade territorial e populacional que caracteriza o Brasil, a reforma agrária que tem sido desenvolvida nesse país envolve um grande leque de espaços, contextos e sujeitos. Ela emerge como expressão das lutas de diversos tipos de camponeses como os sem-terra, que desenvolvem territorialidades agropecuárias; os extrativistas, que desenvolvem territorialidades agroflorestais e os ribeirinhos, que possuem na pesca um dos componentes da sua identidade.

Assim, nesse artigo foi tomado o exemplo de Minas Gerais, o qual denota que as diferentes políticas de obtenção de terras estão relacionadas a um amplo leque de elementos que caracteriza a Questão Agrária estadual, assim como a processos de governança territorial entre os diferentes entes administrativos. Entendendo os assentamentos como trunfos e triunfos do campesinato na luta pela terra, constatou-se que mesmo nos casos em que eles não tiveram origem na desapropriação de terras, ao menos eles têm impedido o avanço do agronegócio.

Demonstrou-se que em Minas Gerais a desapropriação de terras tem sido a política de obtenção mais utilizada. Em grande parte, isso se dá como uma resposta do Estado à pressão dos movimentos socioterritoriais por meio das ocupações de terras e das manifestações. Os principais beneficiários desse tipo de ação são os camponeses sem-terra organizados por movimentos socioterritoriais como o MST.

Também possui destaque o reconhecimento, que no caso dessa unidade federativa, expressa-se majoritariamente como uma forma de compensação social de famílias atingidas pela construção de barragens. Esses assentamentos são criados pelo Governo Estadual e depois, reconhecidos pelo Governo Federal como forma de 
possibilitar às famílias beneficiárias a participação em políticas públicas de instalação produtiva, fomento produtivo, geração de renda ou conquista/garantia de direitos.

Em menor proporção aparecem as seguintes políticas de obtenção de terras: adjudicação, compra e venda, doação e transferência. Assim como a desapropriação e o reconhecimento elas expressam a diversidade dos elementos que caracterizam a Questão Agrária em Minas Gerais, assim como as dinâmicas que estão atreladas ao processo de governança da terra por parte dos governos Estadual e Federal.

\section{Referências}

ALMEIDA, Alfredo Wagner. Agroestratégias e desterritorialização: os direitos territoriais e étnicos na mira dos estrategistas dos agronegócios. In: ALMEIDA, ALFREDO WAGNER et al. (Org.). Capitalismo globalizado e recursos territoriais: fronteiras da acumulação no Brasil contemporâneo. Rio de Janeiro: Lamparina, 2010. p. 101-143.

CLEPS JR, João et al. Conjuntura das lutas sociais em Minas Gerais no Pós-golpe de 2016. Boletim DATALUTA, Presidente Prudente, n. 129, p. 2-8, 2018.

COCA, Estevan Leopoldo de Freitas et al. A luta pela/na terra em tempos de instabilidade institucional: o acampamento Quilombo Campo Grande, em Campo do Meio - MG. Boletim DATALUTA, Presidente Prudente, n. 31, p. 2-9, 2018.

COCA, Estevan Leopoldo de Freitas. Identidade dos camponeses assentados no território Cantuquiriguaçu, Paraná-Brasil. Mercator, Fortaleza, v. 14, n. 1, p. 77-88, 2015. https://doi.org/10.4215/RM2015.1401.0005

COCA, Estevan Leopoldo de Freitas. Um estudo da diversidade e atualidade da reforma agrária: análise dos tipos de assentamentos rurais do território Cantuquiriguaçu - estado do Paraná. 2011. Dissertação (Mestrado em Geografia). Universidade Estadual Paulista (Unesp), Presidente Prudente.

COCA, Estevan Leopoldo de Freitas. Territorialidades camponesas nos tipos de assentamentos rurais do Território Cantuquiriguaçu, estado do Paraná, Brasil. Geographos, Alicante, v. 4, p. 378-403, 2013. https://doi.org/10.14198/GEOGRA2013.4.48

FERNANDES, Bernardo Mançano. A formação do MST no Brasil: Petrópolis: Vozes, 2000.

FERNANDES, Bernardo Mançano. Questão Agrária: conflitualidade e desenvolvimento territorial. In: BUAINAIN, Antônio Márcio (Org.). Luta pela terra, reforma agrária e gestão de conflitos no Brasil. Campinas: Editora UNICAMP, 2008. p. $173-224$. 
FERNANDES, Bernardo Mançano. Transformaciones en el Brasil agrario en las fases neoliberales y posneoliberal: construyendo una política agraria para un desarrollo sustentable. In: RUBIO, BLANCA (Org.). América Latina en la mirada las transformaciones rurales en la transición capitalista. Ciudad de México: Universidad Nacional Autónoma de México, 2018. p. 93-132.

GARCÍA NOSSA, Antonio. Sociologia de la reforma agrária em América Latina. Buenos Aires: Amorrotu, 1973.

GIRARDI, Eduardo Paulon. Proposição teórico-metodológica de uma cartografia geográfica crítica e sua aplicação no desenvolvimento do atlas da questão agrária brasileira. 2008. Tese (Doutorado em Geografia). Universidade Estadual Paulista (Unesp), Presidente Prudente. https://doi.org/10.4000/confins.5631

GRIFFIN, Keith; KHAN, Azizur Rahman; ICKOWITZ, Amy. Poverty and the distribution of land. Journal of Agrarian Change, Oxford, v. 2, n. 3, p. 279-330, 2002. https://doi.org/10.1111/1471-0366.00036

HARVEY, David. O novo imperialismo. São Paulo: Loyola, 2005.

IANNI, Otávio. Colonização e contra-reforma agrária na Amazônia. Petrópolis: Vozes, 1979.

LADEIA, James Eustáquio Barbosa. Quando o campo encontra a cidade: análise do assentamento Herbert de Souza - Betinho no distrito de Engenheiro Dolabela (Bocaiúva, MG). 2003. Dissertação (Mestrado em Ciências Sociais). Pontifícia Universidade Católica de Minas Gerais (PUC), Belo Horizonte.

MST - MOVIMENTO DOS TRABALHADORES RURAIS SEM-TERRA. Assentamento Resistência: uma história de luta que nunca acaba - Movimento dos Trabalhadores Rurais Sem Terra. 2018. Disponível em: http://www.mst.org.br/2018/04/04/assentamento-resistencia-uma-historia-de-luta-quenunca-acaba.html. Acesso em: 1 out. 2019.

OLIVEIRA, Ariovaldo Umbelino De. Modo capitalista de produção, agricultura e reforma agrária. São Paulo: FFLHC, 2007.

RAFFESTIN, Claude. Por uma Geografia do poder. São Paulo: Ática, 1993.

REDE DATALUTA. Relatório DATALUTA Brasil - 2017. Presidente Prudente, 2018.

Van der PLOEG, Jan Douwe. Camponeses e a arte da agricultura. São Paulo/Porto Alegre: EdUNESP/Editora UFRGS, 2016.

WHITE, Ben; BORRAS JR., Saturnino M.; HALL, Ruth. Land Reform. In: CURRIEALDER, Bruce et al. (Org.). Development: ideas, experience and prospects. Oxfor: Oxford University Press, 2014. p. https://doi.org/10.1093/acprof:oso/9780199671656.003.0029 